\title{
Expression of copper-transporting P-type adenosine triphosphatase (ATP7B) correlates with cisplatin resistance in human non-small cell lung cancer xenografts
}

\author{
TOMOKI NAKAGAWA ${ }^{1}$, YOSHIMASA INOUE ${ }^{2}$, HIROKO KODAMA $^{3}$, HITOSHI YAMAZAKI $^{4}$, \\ KENJI KAWAI $^{5}$, HIROSHI SUEMIZU ${ }^{5}$, RYOTA MASUDA ${ }^{1}$, MASAYUKI IWAZAKI ${ }^{1}$, \\ SHUNSUKE YAMADA $^{2}$, YOSHITO UEYAMA ${ }^{6}$, HIROSHI INOUE ${ }^{1}$ and MASATO NAKAMURA ${ }^{5,7}$ \\ ${ }^{1}$ Department of General Thoracic Surgery, Tokai University School of Medicine, Bohseidai, Isehara, \\ Kanagawa 259-1193, ${ }^{2}$ Department of General Thoracic Surgery, Tokai University Hachioji Hospital, \\ Ishikawa-cho, Hachioji, Tokyo 192-0032, ${ }^{3}$ Department of Pediatrics, Teikyo University School of \\ Medicine, 2-11-1, Kaga, Itabashi-ku, Tokyo 173-8605, ${ }^{4}$ Department of Pathology, Tokai University \\ Tokyo Hospital, 1-2-5 Yoyogi, Shibuya-ku, Tokyo 151-0053, ${ }^{5}$ Central Institute for Experimental \\ Animals, Nogawa 1430, Kwasaki, Kanagawa 216-0003, ${ }^{6}$ Department of Pathology, Tokai University \\ School of Medicine, Bohseidai, Isehara, Kanagawa 259-1193, ${ }^{7}$ Department of Pathology, \\ Tokai University Hachioji Hospital, Ishikawa-cho, Hachioji, Tokyo 192-0032, Japan
}

Received March 17,2008; Accepted April 21, 2008

DOI: 10.3892/or_00000002

\begin{abstract}
Copper-transporting P-type adenosine triphosphatase (ATP7B) is reportedly associated with platinum drug resistance in various solid carcinomas. However, the impact of ATP7B on platinum drug resistance in non-small cell lung cancer (NSCLC) remains unknown. We investigated ATP7B expression in nine human NSCLC xenografts using real-time polymerase chain reaction (PCR) and immunohistochemistry, and examined the relationship between the expression level of ATP7B and in vivo cisplatin (CDDP) sensitivity. ATP7B mRNA expression was significantly correlated with in vivo cisplatin sensitivity [coefficient of determination $\left(\mathrm{R}^{2}\right)=0.949$, $\mathrm{p}=0.005]$. ATP7B protein was detected in the nine xenografts. The ATP7B protein expression level was comparable to that of ATP7B mRNA. ATP7B mRNA and protein expression levels in the CDDP-resistant xenografts were significantly higher than those in the CDDP-sensitive xenografts $(\mathrm{p}=0.0389$ and $\mathrm{p}=0.0357$, respectively, Mann-Whitney $\mathrm{U}$ test). These results suggest that $\mathrm{ATP} 7 \mathrm{~B}$ is a CDDP-resistance marker in human NSCLC xenografts in vivo.
\end{abstract}

Correspondence to: Dr Yoshimasa Inoue, Department of General Thoracic Surgery, Tokai University Hachioji Hospital, Ishikawacho, Hachioji, Tokyo 192-0032, Japan

E-mail: yoshimas@is.icc.u-tokai.ac.jp

Key words: non-small cell lung cancer, xenograft, adenosine triphosphatase, cisplatin

\section{Introduction}

The anticancer drug, cisplatin (CDDP), which contains platinum, is widely used for the treatment of solid tumors such as testicular, ovarian, cervical, bladder, head and neck and non-small cell lung cancers (NSCLC) (1). CDDP has been a key drug in chemotherapy regimens against NSCLC for $>20$ years. However, the overall response rate to cisplatin as a single agent against NSCLC is $<20 \%$ (2). Furthermore, the development of resistance to CDDP is common during the treatment of NSCLC patients and is a major concern for clinical oncologists. Thus, exploring chemoresistance marker is a very important issue. The CDDP-resistance mechanisms include decreased drug accumulation, enhanced detoxification and increased DNA repair efficiency. However, studies are limited mainly to the in vitro or in vivo level, and none of these mechanisms have been validated as common contributors to clinical CDDP resistance and prognosis in patients with NSCLC (3).

Copper-transporting P-type adenosine triphosphatase (ATP7B) plays a key role in copper distribution inside cells. ATP7B is expressed in liver and kidney and to a lesser extent in brain tissues in normal individuals $(4,5)$. ATP7B is responsible for the export of copper from the liver, while mutations that disable the function of ATP7B lead to excessive hepatic copper accumulation because of impaired biliary copper excretion in patients with Wilson's disease (5-8). Studies have suggested that the copper export system also functions as an efflux transporter for platinum drugs, and the immunohistochemical expression of ATP7B has been shown to be associated with resistance against platinum drugs in some solid tumors $(3,9-15)$. However, ATP7B expression and its impact on CDDP resistance in NSCLC has yet to be reported. 
Table I. Characteristics of xenografts with reference to histology, ATP7B expression level and in vivo sensitivity to cisplatin.

\begin{tabular}{lccccc}
\hline Xenograft & Histology & ATP7B expression (mRNA) & ATP7B expression (IHC) & ${\text { \% } / \mathrm{C}^{\mathrm{b}}}^{\mathrm{a}}$ & In vivo sensitivity $^{\mathrm{c}}$ \\
\hline LC-1-JCK & Squamous & 0.038 & ++ & 41 & $\mathrm{~S}$ \\
LC-6-JCK & Large & 0.214 & +++ & 70 & $\mathrm{R}$ \\
LC-7-JCK & Adeno & 0.049 & ++ & 46 & $\mathrm{~S}$ \\
LC-11-JCK & Adeno & 0.218 & +++ & $\underline{62}$ & $\mathrm{R}$ \\
LC-17-JCK & Adeno & 0.279 & +++ & $\mathrm{R}$ & $\mathrm{R}$ \\
LC-52-JCK & Squamous & 0.032 & ++ & 60 & $\mathrm{~S}$ \\
LC-55-JCK & Large & 0.119 & +++ & $\underline{65}$ & $\mathrm{R}$ \\
LC-58-JCK & Adeno & 0.110 & +++ & $\mathrm{62}$ & $\mathrm{R}$ \\
LC-61-JCK & Squamous & 0.043 & + & $\mathrm{R}$ \\
\hline
\end{tabular}

${ }^{a} \mathrm{IHC}$, immunohistochemical staining. The scoring system was described as follows:,$- 0 ;+, 0-25 ;++, 26-75$ and,$+++ 76-100 \%$. ${ }^{\text {b }} \%$ T/C, growth ratio calculated as the relative volume of the treated xenografts to the volume of the untreated (control) xenografts on Day 14 of treatment. The underlined number represents $\mathrm{T} / \mathrm{C}$ value obtained with the administration of the maximum tolerated dose (MTD) of CDDP (10 mg/kg). The plain number represents the T/C value obtained with the administration of the clinical equivalent dose (CED) of CDDP (7 mg/ $\mathrm{kg}){ }^{\mathrm{c}} \mathrm{In}$ vivo sensitivity; S, sensitive and R, resistant.

In this study, we investigated the relationship between the expression of ATP7B and CDDP resistance in human NSCLC xenografts. We examined ATP7B expression in nine human NSCLC xenografts using real-time polymerase chain reaction (PCR) and immunohistochemistry, and analyzed the relationship between the expression level of ATP7B and in vivo cisplatin (CDDP) sensitivity.

\section{Materials and methods}

Cell line. A human colorectal cancer cell line (HCT8) was obtained from RIKEN (Saitama, Japan). The cell line was cultured at $37^{\circ} \mathrm{C}$ in Dulbecco's modified Eagle's medium (containing $10 \%$ bovine serum) under a $5 \%$ atmosphere.

Xenografts and the in vivo chemosensitivity test. We employed a panel of nine xenografts (4 adenocarcinoma, 3 squamous cell carcinomas and 2 large cell carcinomas). In vivo chemosensitivity tests were performed according to previously reported procedures (16-18). CDDP was obtained from Nihon Kayaku (Tokyo, Japan), dissolved in saline and used for the in vivo chemosensitivity tests.

Female nude mice with a BALB/c background (BALB/c$\mathrm{nu} / \mathrm{nu}$ ) were used at 6-8 weeks of age according to the animal care guidelines of the Central Institute for Experimental Animals. Nude mice (BALB/c-nu/nu) bearing xenografts (tumor volume: $100-300 \mathrm{~mm}^{3}$ ) were selected and divided into groups of six. CDDP was administered intravenously in a single dose. The doses that were adopted were the maximum tolerated dose (MTD) of CDDP $(10 \mathrm{mg} / \mathrm{kg})$ and the clinical equivalent dose (CED) of CDDP (7 mg/kg).

The antitumor effect was assessed 14 days after the start of treatment. The tumor growth rate was calculated by dividing the volume 14 days after the start of treatment $\left(\mathrm{V}_{14}\right)$ by the volume on the day treatment was started $\left(\mathrm{V}_{0}\right)$, and the relative tumor growth rate $(\% \mathrm{~T} / \mathrm{C})$ was obtained as a ratio of the treated group to the control group. The drug was considered effective when the relative tumor growth rate was $50 \%$ or less and a significant difference from the control group was observed using the Mann-Whitney U test ( $\mathrm{p}<0.01$, one-sided). The therapeutic experiments were conducted first at the MTD and then at the CED. The CED was lower than the MTD for CDDP. Testing at the CED level was omitted if the treatment results showed the MTD to be ineffective, since it was obvious that the CED would also be ineffective. Xenografts were dichotomized into CDDP-resistant (R) and CDDP-sensitive groups (S). Each xenograft was judged as resistant when the MTD or CED of CDDP was ineffective, and it was judged as sensitive when the CED of CDDP was effective.

Quantitative evaluation of ATP7B mRNA expression. Total RNA was extracted from xenograft samples and the cell line using the acid guanidinium thiocyanate-phenol-chloroform extraction (AGPC) method. Complementary DNA (cDNA) was synthesized from $1 \mu \mathrm{g}$ of total RNA according to our previous report $(18,19)$.

Real-time PCR assays were run on an ABI PRISM 7000 sequence detection system (Perkin-Elmer Applied Biosystems). PCR was performed according to the manufacturer's recommendation and the protocols of other published studies $(20,21)$. Briefly, a total volume of $50 \mu 1$ of reaction mixture containing $1 \mu \mathrm{l}$ of cDNA template, $25 \mu \mathrm{l}$ of Taq Man Universal PCR Master Mix (Perkin-Elmer Applied Biosystems), and $2.5 \mu 1$ of primer probe mixture for ATP7B and $\beta$-actin were amplified as follows: after the initial denaturation (2 min at $95^{\circ} \mathrm{C}$ ), amplification was performed with 50 cycles of $15 \mathrm{sec}$ at $95^{\circ} \mathrm{C}$ and $60 \mathrm{sec}$ at $60^{\circ} \mathrm{C}$. The primer probe mixture for ATP7B [Taq Man (R) gene expression assays, with the assay ID being: Hs00163739_m1, Perkin-Elmer Applied Biosystems] and $B$-actin (human ACTB, 4310881E, Perkin-Elmer Applied Biosystems) were purchased as part of the commercial kits.

To quantify the ATP7B gene transcripts precisely, we monitored the $B$-actin transcripts as the quantitative control and each sample was normalized on the basis of its B-actin transcript content. Standard curves for ATP7B and B-actin mRNA were generated using serially diluted solutions $(1 / 5$, 


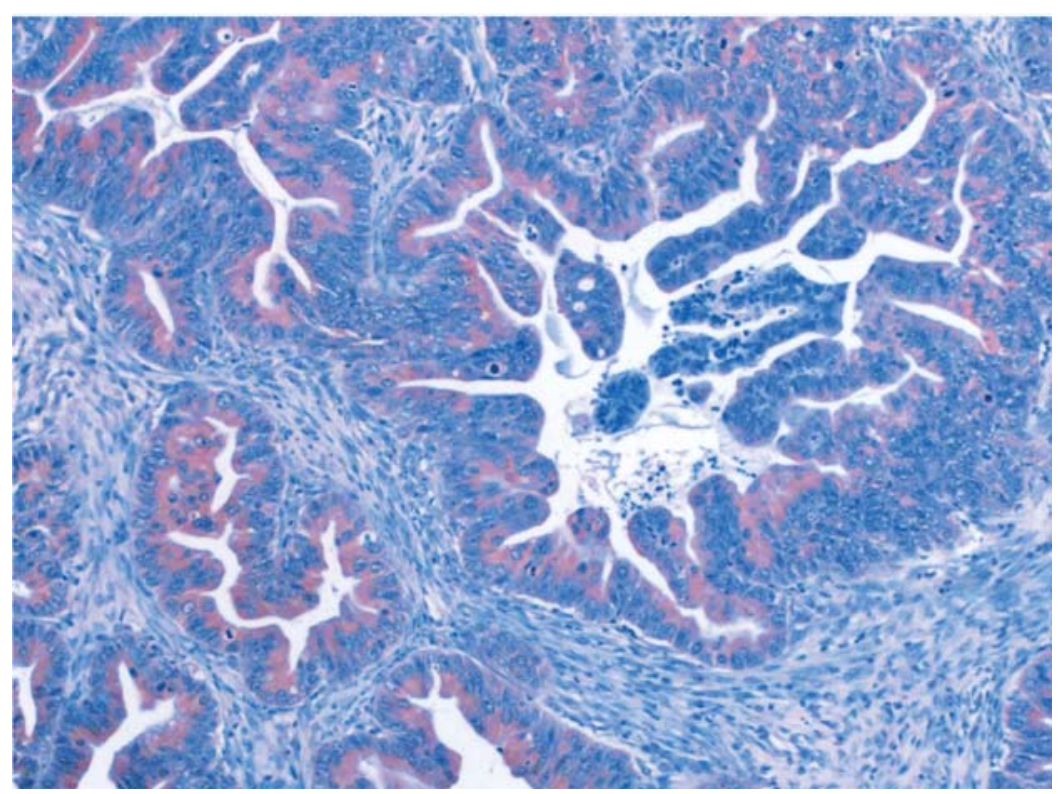

Figure 1. Cytoplasmic immunoreactivity for ATP7B protein expression in a human NSCLC xenograft (LC-17-JCK, adenocarcinoma).

$1 / 25,1 / 125$ and $1 / 625)$ of HCT8 cDNA. After determining the threshold cycle $(\mathrm{Ct})$, which was defined as the PCR cycle number at which point the fluorescent intensity exceeded the threshold, the amount of target gene expression was calculated from the standard curve, and quantitative normalization of cDNA in each sample was performed using the expression of the $B$-actin gene as an internal control. Finally, the ATP7B mRNA levels were expressed as a ratio to the $B$-actin mRNA levels. Real-time PCR assays were conducted in duplicate on one dish for each sample, and the mean value was used to calculate the mRNA expression levels.

Immunohistochemical staining. Immunohistochemistry was performed using 4- $\mu \mathrm{m}$ sections cut from formalin-fixed, paraffin-embedded specimens and the commercially available streptavidin-biotin complex-alkaline phosphatase method (22). Polyclonal rabbit anti-human ATP7B antibody was kindly provided by Dr Hiroko Kodama of the Teikyo University School of Medicine. After $24 \mathrm{~h}$ of incubation with the primary antibody at $4^{\circ} \mathrm{C}$, the sections were incubated with Histofine simple stain MAX-PO(M) (Nichirei Corporation, Tokyo, Japan) for $60 \mathrm{~min}$, and the immunoreacted cells were visualized using simple stain DAB solution (Nichirei Corporation). The sections were lightly counterstained with hematoxylin.

Each slide was evaluated using light microscopy and the staining was graded semiquantitatively: -, no immunostaining; ,$+ 1-25 \%$ of the tumor cells stained positive;,$++ 26-75 \%$ of the tumor cells stained positive and,$+++>75 \%$ of the tumor cells stained positive.

Statistical analysis. The simple linear regression model was used to assess the relation between ATP7B mRNA expression and the relative tumor growth rate $(\% \mathrm{~T} / \mathrm{C})$. The MannWhitney U test was used to compare ATP7B expression in the CDDP-resistant and the CDDP-sensitive tumors. The tests were two-sided, and statistical significance was set at $\mathrm{p}<0.05$.
The statistical analysis was performed using StatView ver. 5 software (SAS Institute Inc., Cary, NC, USA).

\section{Results}

ATP7B mRNA expression. Table I shows the ATP7B mRNA expression level of each of the human NSCLC xenografts. The ATP7B mRNA expression levels ranged from 0.032 to 0.279 (mean \pm standard deviation: $0.126 \pm 0.090$ ). The five xenografts whose ATP7B expression was $>0.1$ were regarded as resistant to CDDP. The primers of human ATP7B showed no cross amplification in murine tissues (brain, heart, lung, kidney, liver and skin) using real-time PCR.

ATP7B protein expression. ATP7B protein expression in each of the xenografts was confirmed by immunohistochemical staining. A variable degree of cytoplasmic staining of ATP7B in the tumor cells was observed in the nine xenograft lines employed in this study (Table I). Five ' +++ ' cases and one '++' case occurred in the R group and two '++' cases and one ' + ' case occurred in the $\mathrm{S}$ group. These results did not conflict with the real-time PCR findings. A representative case is shown in Fig. 1.

In vivo chemosensitivity test. The results of the in vivo sensitivity test are summarized in Table I. According to the protocol described in Materials and methods, the therapeutic experiments were conducted first at the MTD for the nine xenografts, and 4 out of 9 xenografts (LC-11-JCK, LC-17JCK, LC-58-JCK and LC-61-JCK) were unaffected by CDDP at the MTD and were judged to be the resistant (R) group. The $\% \mathrm{~T} / \mathrm{C}$ values at the MTD of CDDP for xenografts LC-11-JCK, LC-17-JCK, LC-58-JCK and LC-61-JCK were 62, 56, 65 and 62 , respectively.

The other 5 xenografts (LC-1-JCK, LC-6-JCK, LC-7-JCK, LC-52-JCK and LC-55-JCK) were affected by CDDP at the MTD. Consequently, their in vivo CDDP sensitivities at the 


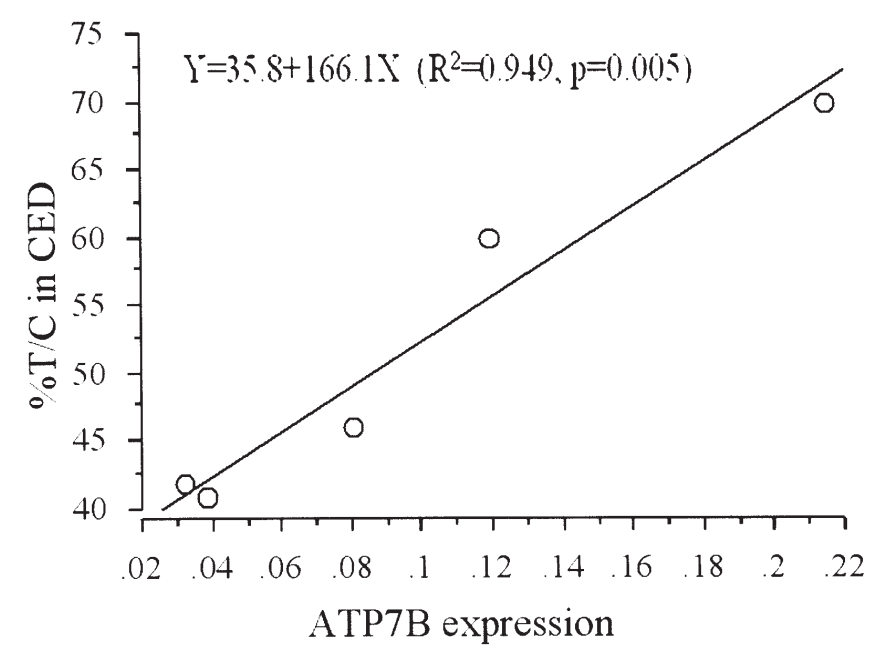

Figure 2. The relation between ATP7B mRNA expression and the relative tumor growth rate $(\% \mathrm{~T} / \mathrm{C})$. The ATP7B mRNA expression levels were plotted against the relative tumor growth rate $(\% \mathrm{~T} / \mathrm{C})$ at the clinical equivalent dose (CED, $7 \mathrm{mg} / \mathrm{kg}$ ) of cisplatin. ATP7B was plotted on the horizontal axis and $\% \mathrm{~T} / \mathrm{C}$ on the vertical axis. A simple regression line was then drawn. The regression equation was as follows: $\mathrm{Y}=35.8+166.1 \mathrm{X}(\mathrm{X}$ : ATP7B expression level and Y: \% T/C at the CED of CDDP), and the coefficient of determination $\left(\mathrm{R}^{2}\right)$ was $0.949(\mathrm{p}=0.005)$. This result suggests that ATP7B mRNA expression was strongly correlated with in vivo CDDP sensitivity.

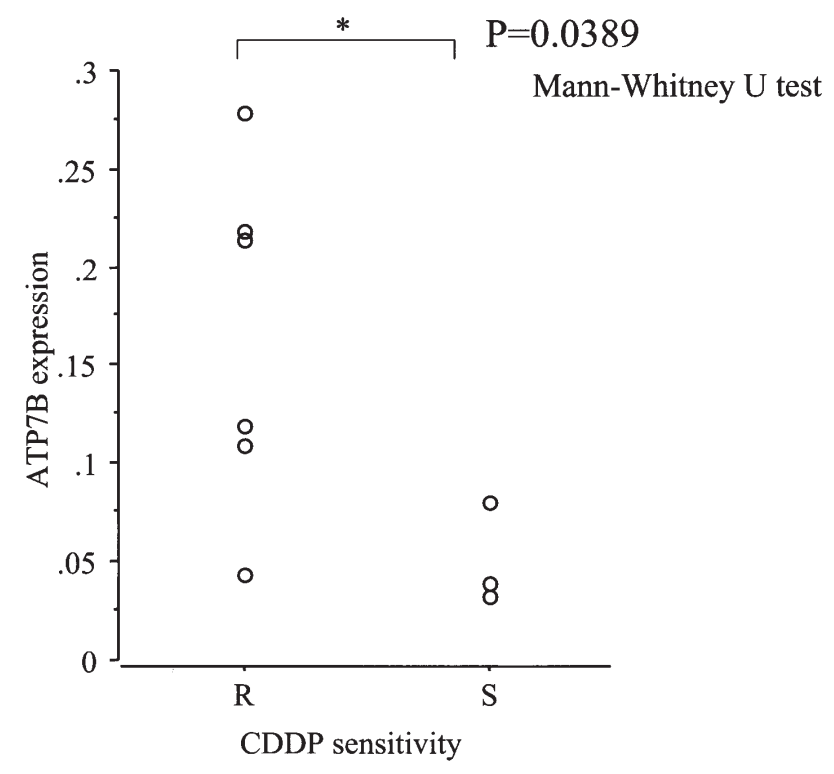

Figure 3. ATP7B mRNA expression level and in vivo cisplatin sensitivity.

CED $(7 \mathrm{mg} / \mathrm{kg})$ were evaluated. The $\% \mathrm{~T} / \mathrm{C}$ values at the CED of CDDP for xenografts LC-6-JCK and LC-55-JCK were 70 and 60 , respectively. The two xenografts were judged as being resistant (R) to CDDP. In contrast, the $\% \mathrm{~T} / \mathrm{C}$ values at the CED of CDDP for xenografts LC-1-JCK, LC-7-JCK and LC-52-JCK were 41, 46 and 42, respectively. The xenografts were judged to be sensitive (S) to CDDP.

Relationship between the ATP7B expression and CDDP sensitivity. To examine the possible associations between the
Table II. ATP7B protein expression level and in vivo sensitivity to cisplatin.

\begin{tabular}{|c|c|c|c|c|}
\hline & \multicolumn{3}{|c|}{ ATP7B expression $\left(\mathrm{IHC}^{\mathrm{a}}\right)$} & \\
\hline & + & ++ & +++ & \\
\hline \multicolumn{5}{|c|}{ In vivo sensitivity } \\
\hline $\mathrm{S}$ & 1 & 2 & 0 & $\mathrm{p}^{\mathrm{b}}=0.0357$ \\
\hline $\mathrm{R}$ & 0 & 1 & 5 & \\
\hline
\end{tabular}

${ }^{a} \mathrm{IHC}$, immunohistochemical staining. The scoring system was: -, 0; ,$+ 0-25 ;++, 26-75$ and +++, 76-100\%. ${ }^{\mathrm{b}} \mathrm{p}, \mathrm{p}$-value, evaluated by Mann-Whitney $\mathrm{U}$ test. ${ }^{\mathrm{c}}$ In vivo sensitivity; $\mathrm{S}$, sensitive and $\mathrm{R}$, resistant.

ATP7B mRNA expression level and CDDP resistance in NSCLC xenografts, the ATP7B mRNA expression levels were plotted against the $\% \mathrm{~T} / \mathrm{C}$ at the CED and MTD of CDDP. The ATP7B mRNA expression level was plotted on the horizontal axis and the $\% \mathrm{~T} / \mathrm{C}$ on the vertical axis. A simple regression line was then drawn.

When the $\% \mathrm{~T} / \mathrm{C}$ at the CED was adopted, the regression equation was as follows: $\mathrm{Y}=35.8+166.1 \mathrm{X}(\mathrm{X}$ : ATP7B expression level and $\mathrm{Y}: \% \mathrm{~T} / \mathrm{C}$ at the $\mathrm{CED}$ of $\mathrm{CDDP})$, and the coefficient of determination $\left(\mathrm{R}^{2}\right)$ was 0.949 ( $\mathrm{p}=0.005$, Fig. 2). These results suggest that ATP7B mRNA expression was strongly correlated with the in vivo sensitivity of CDDP at the CED. No significant correlation was detected between the ATP7B mRNA expression level and CDDP sensitivity at the MTD (data not shown).

The difference in ATP7B expression between the CDDPresistant ( $\mathrm{R}$ group, $\mathrm{n}=6$ ) and the $\mathrm{CDDP}$-sensitive xenografts ( $\mathrm{S}$ group, $\mathrm{n}=3$ ) was also evaluated. The ATP7B mRNA expression levels in the $\mathrm{R}$ group were significantly higher than those in the $\mathrm{S}$ group (Fig. 3, p=0.0389, Mann-Whitney U test). The same tendency was also observed for immunohistochemistry. The ATP7B protein expression levels in the R group were significantly higher than those in the $\mathrm{S}$ group (Table II, $\mathrm{p}=0.0357$, Mann-Whitney U test).

\section{Discussion}

In the present study, we confirmed the expression of ATP7B in NSCLC using real-time PCR and immunohistochemistry. Our findings suggest that the ATP7B expression level may be useful as a chemoresistance marker in NSCLC. To our knowledge, this is the first report to evaluate ATP7B expression and its possible significance as a chemoresistance marker in NSCLC.

ATP7B is a member of a class of heavy metal-transporting P-type ATPases that pump copper, cadmium, zinc, silver or lead $(6,7,9,23)$. Copper is an essential trace element and is transported to the extracellular environment by an energydependent system. Alterations in copper homeostasis can cause severe problems (23). For example, Wilson's disease, an autosomal recessive disease of copper transport, is characterized by chronic liver and/or neurological disorders, sometimes accompanied by kidney damage $(14,24)$. 
ATP7B mRNA expression was reported to be associated with in vitro cisplatin resistance in ovarian carcinoma cell lines (25). The ATP7B gene was also induced by exposure to cisplatin in human prostate cells $(9,26)$. Transfection of epidermoid, head and neck and ovarian carcinoma cells with an ATP7B expression vector rendered them resistant to platinum drugs, such as cisplatin, carboplatin and oxaliplatin $(9,12,26)$. These ATP7B-transfeted cells not only exhibited reduced intracellular concentrations but also an increased efflux of these platinum drugs $(9,12)$.

Immunohistochemistry and mRNA analysis have demonstrated the possible clinical significance of ATP7B expression in various solid tumors $(13-15,27,28)$. A higher expression level of ATP7B is correlated with an unfavorable response to platinum drug treatment in ovarian, esophagealand oral squamous cell carcinoma (13-15). In ovarian carcinoma, ATP7B-positive tumors have an inferior response to chemotherapy, and patients with such tumors have a poorer diseasefree and overall survival than those with ATP7B-negative tumors (15). In endometrial carcinoma, ATP7B-positive expression was a significant prognostic factor (29). Although these published data provide strong evidence that ATP7B mediates resistance to platinum drugs, ATP7B expression in NSCLC tissues has yet to be reported.

In this study, we evaluated the gene expression levels of ATP7B in nine NSCLC xenografts using a real-time PCR assay and immunohistochemistry. A very strong correlation was found between ATP7B expression and the \% $\mathrm{T} / \mathrm{C}$ at the CED. Moreover, the level of ATP7B mRNA expression in the CDDP-resistant group (R) was significantly higher than that in the CDDP-sensitive group (S).

ATP7B protein expression was also immunohistochemically confirmed in the cytoplasm of the nine xenografts employed in this study. ATP7B has been reported to be abundant in the Golgi apparatus, and has been detected in the cytoplasm of normal tissue and other types of solid malignancies (3). The staining pattern in our study was consistent with these previous reports. In addition, the ATP7B protein expression level was comparable to that of ATP7B mRNA in each of the xenografts. The ATP7B protein expression levels in the $\mathrm{R}$ group were significantly higher than those in the $\mathrm{S}$ group.

These findings suggest that ATP7B expression is associated with CDDP resistance in NSCLC xenografts and that ATP7B expression may be a useful chemoresistance marker for cisplatin. Knowledge of the ATP7B expression levels in NSCLC tissues obtained by surgery or biopsy may provide important information for determining the subsequent treatment strategy, such as the optimal choice of chemotherapeutic agents and molecular-targeted therapy to ameliorate cisplatin resistance.

Further studies are needed to clarify the clinical significance of ATP7B expression in NSCLC. Comparing the clinical response or survival after treatment with cisplatin-based chemotherapy with the ATP7B expression level in NSCLC would likely provide significant new data.

\section{References}

1. Perez RP: Cellular and molecular determinants of cisplatin resistance. Eur J Cancer 34: 1535-1542, 1998.
2. Tiseo M, Franciosi V, Grossi F and Ardizzoni A: Adjuvant chemotherapy for non-small cell lung cancer: ready for clinical practice? Eur J Cancer 42: 8-16, 2006.

3. Katoh R, Takebayashi Y and Takenoshita S: Expression of copper-transporting P-type adenosine triphosphatase (ATP7B) as a chemoresistance marker in human solid carcinomas. Ann Thorac Cardiovasc Surg 11: 143-145, 2005.

4. Tanzi RE, Petrukhin K, Chernov I, Pellequer JL, Wasco W, Ross B, Romano DM, et al: The Wilson disease gene is a copper transporting ATPase with homology to the Menkes disease gene. Nat Genet 5: 344-350, 1993.

5. Safaei R, Holzer AK, Katano K, Samimi G and Howell SB: The role of copper transporters in the development of resistance to Pt drugs. J Inorg Biochem 98: 1607-1613, 2004.

6. Roberts EA and Cox DW: Wilson disease. Baillieres Clin Gastroenterol 12: 237-256, 1998.

7. Terada K, Schilsky ML, Miura N and Sugiyama T: ATP7B (WND) protein. Int J Biochem Cell Biol 30: 1063-1067, 1998.

8. Safaei R: Role of copper transporters in the uptake and efflux of platinum containing drugs. Cancer Lett 234: 34-39, 2006.

9. Komatsu M, Sumizawa T, Mutoh M, Chen ZS, Terada K, Furukawa T, Yang XL, et al: Copper-transporting P-type adenosine triphosphatase (ATP7B) is associated with cisplatin resistance. Cancer Res 60: 1312-1316, 2000.

10. Katano K, Kondo A, Safaei R, Holzer A, Samimi G, Mishima M, Kuo YM, et al: Acquisition of resistance to cisplatin is accompanied by changes in the cellular pharmacology of copper. Cancer Res 62: 6559-6565, 2002.

11. Nakayama K, Kanzaki A, Ogawa K, Miyazaki K, Neamati N and Takebayashi Y: Copper-transporting P-type adenosine triphosphatase (ATP7B) as a cisplatin based chemoresistance marker in ovarian carcinoma: comparative analysis with expression of MDR1, MRP1, MRP2, LRP and BCRP. Int J Cancer 101: 488-495, 2002.

12. Katano K, Safaei R, Samimi G, Holzer A, Rochdi M and Howell SB: The copper export pump ATP7B modulates the cellular pharmacology of carboplatin in ovarian carcinoma cells. Mol Pharmacol 64: 466-473, 2003

13. Miyashita H, Nitta Y, Mori S, Kanzaki A, Nakayama K, Terada K, Sugiyama T, et al: Expression of copper-transporting P-type adenosine triphosphatase (ATP7B) as a chemoresistance marker in human oral squamous cell carcinoma treated with cisplatin. Oral Oncol 39: 157-162, 2003.

14. Higashimoto M, Kanzaki A, Shimakawa T, Konno S, Naritaka Y, Nitta Y, Mori S, et al: Expression of copper-transporting P-type adenosine triphosphatase in human esophageal carcinoma. Int $\mathrm{J}$ Mol Med 11: 337-341, 2003.

15. Nakayama K, Kanzaki A, Terada K, Mutoh M, Ogawa K, Sugiyama T, Takenoshita S, et al: Prognostic value of the $\mathrm{Cu}-$ transporting ATPase in ovarian carcinoma patients receiving cisplatin-based chemotherapy. Clin Cancer Res 10: 2804-2811, 2004.

16. Fujimori S, Abe Y, Nishi M, Hamamoto A, Inoue $\mathrm{Y}$, Ohnishi $\mathrm{Y}$, Nishime C, et al: The subunits of glutamate cysteine ligase enhance cisplatin resistance in human non-small cell lung cancer xenografts in vivo. Int J Oncol 25: 413-418, 2004.

17. Inaba $\mathrm{M}$ and Tashiro $\mathrm{T}$ : Therapeutic effects on various types of human cancers and clinical correlation. In: The Nude Mouse and Anticancer Drug Evaluation. Nomura T, Sakurai Y and Inaba M (eds). Central Institute for Experimental Animals, Kanagawa, pp43-87, 1996.

18. Abe Y, Ohnishi Y, Yoshimura M, Ota E, Ozeki Y, Oshika Y, Tokunaga $\mathrm{T}$, et al: $\mathrm{P}$-glycoprotein-mediated acquired multidrug resistance of human lung cancer cells in vivo. $\mathrm{Br} \mathrm{J}$ Cancer 74: 1929-1934, 1996.

19. Inoue Y, Tomisawa M, Yamazaki H, Abe Y, Suemizu H, Tsukamoto H, Tomii Y, et al: The modifier subunit of glutamate cysteine ligase (GCLM) is a molecular target for amelioration of cisplatin resistance in lung cancer. Int J Oncol 23: 1333-1339, 2003.

20. Heid CA, Stevens J, Livak KJ and Williams PM: Real time quantitative PCR. Genome Res 6: 986-994, 1996.

21. Shintani Y, Ohta M, Hirabayashi H, Tanaka H, Iuchi K, Nakagawa $\mathrm{K}$, Maeda $\mathrm{H}$, et al: New prognostic indicator for nonsmall-cell lung cancer, quantitation of thymidylate synthase by real-time reverse transcription polymerase chain reaction. Int $\mathbf{J}$ Cancer 104: 790-795, 2003.

22. Inoue Y, Gika M, Abiko T, Oyama T, Saitoh Y, Yamazaki H, Nakamura $\mathrm{M}$, et al: $\mathrm{Bcl}-2$ overexpression enhances in vitro sensitivity against docetaxel in non-small cell lung cancer. Oncol Rep 13: 259-264, 2005. 
23. Harris ED, Qian Y, Tiffany-Castiglioni E, Lacy AR and Reddy MC: Functional analysis of copper homeostasis in cell culture models: a new perspective on internal copper transport. Am J Clin Nutr 67: S988-S995, 1998.

24. Petrukhin K, Lutsenko S, Chernov I, Ross BM, Kaplan JH and Gilliam TC: Characterization of the Wilson disease gene encoding a P-type copper transporting ATPase: genomic organization, alternative splicing, and structure/function predictions. Hum Mol Genet 3: 1647-1656, 1994.

25. Nakayama K, Miyazaki K, Kanzaki A, Fukumoto M and Takebayashi Y: Expression and cisplatin sensitivity of coppertransporting P-type adenosine triphosphatase (ATP7B) in human solid carcinoma cell lines. Oncol Rep 8: 1285-1287, 2001.

26. Katano K, Safaei R, Samimi G, Holzer A, Tomioka M Goodman M and Howell SB: Confocal microscopic analysis of the interaction between cisplatin and the copper transporter ATP7B in human ovarian carcinoma cells. Clin Cancer Res 10: 4578-4588, 2004
27. Kanzaki A, Toi M, Neamati N, Miyashita H, Oubu M, Nakayama K, Bando $\mathrm{H}$, et al: Copper-transporting P-type adenosine triphosphatase (ATP7B) is expressed in human breast carcinoma. Jpn J Cancer Res 93: 70-77, 2002.

28. Ohbu M, Ogawa K, Konno S, Kanzaki A, Terada K, Sugiyama T and Takebayashi Y: Copper-transporting P-type adenosine triphosphatase (ATP7B) is expressed in human gastric carcinoma. Cancer Lett 189: 33-38, 2003.

29. Aida T, Takebayashi Y, Shimizu T, Okamura C, Higasimoto M, Kanzaki A, Nakayama K, et al: Expression of copper-transporting P-type adenosine triphosphatase (ATP7B) as a prognostic factor in human endometrial carcinoma. Gynecol Oncol 97: 41-45, 2005 . 